\title{
Erratum to: Second-Generation Tyrosine Kinase Inhibitors in First-Line Treatment of Chronic Myeloid Leukaemia (CML)
}

\author{
Elisabetta Abruzzese • Massimo Breccia • \\ Roberto Latagliata
}

Published online: 22 March 2014

(c) Springer International Publishing Switzerland 2014

\section{Erratum to: BioDrugs \\ DOI 10.1007/s40259-013-0056-z}

The authors have alerted us to the following error:

Page 7, section 3.5, 3rd paragraph, lines 10-15: The following phrase which reads:

"Porkka et al. [54] showed that the incidence of pleural effusions was significantly reduced with dasatinib $100 \mathrm{mg}$ four times daily compared with dasatinib $50 \mathrm{mg}, 70 \mathrm{mg}$ bid or $140 \mathrm{mg}$ QD (14\% vs. $23-26 \%$, respectively) over a 24-month minimum follow-up."

should read:

"Porkka et al. [54] showed that the incidence of pleural effusions was significantly reduced with dasatinib $100 \mathrm{mg}$ once daily compared with dasatinib $50 \mathrm{mg}, 70 \mathrm{mg}$ bid or $140 \mathrm{mg}$ QD (14\% vs. 23-26\%, respectively) over a 24-month minimum follow-up."

The online version of the original article can be found under doi:10.1007/s40259-013-0056-z.

E. Abruzzese $(\bowtie)$

Hematology, S. Eugenio Hospital, Tor Vergata University,

P. le dell'Umanesimo 10, 00144 Rome, Italy

e-mail: elisabetta.abruzzese@uniroma2.it

M. Breccia

Department of Cellular Biotechnology and Hematology,

Sapienza University, Rome, Italy

e-mail: breccia@bce.uniroma1.it

R. Latagliata

Department of Cellular Biotechnologies and Hematology,

Sapienza University of Rome, Via Benevento 6, Rome, Italy

e-mail: rob.lati@libero.it 